Bioscientia Medicina: Journal of Biomedicine \&

Translational Research

Journal Homepage: www.bioscmed.com

\title{
Comprehensive Obstetric and Neonatal Emergency Services (PONEK) to Reduce Infant Mortality and Improve Maternal Health
}

\section{Irawan Sastradinata ${ }^{*}$}

${ }^{1}$ Department of Obstetric and Gynecology, Faculty of Medicine, Universitas Sriwijaya, Palembang, Indonesia

\author{
A R T I C L E I N F O \\ Keywords: \\ PONEX \\ Hospital \\ Mortalitas \\ Maternal \\ Corresponding author: \\ Irawan Sastradinata \\ E-mail address: \\ wansastra@yahoo.com
}

\begin{abstract}
A B S T R A C T
The Millennium Development Goals (Millennium Development Goal's) in 2015, there are two targets and indicators that are specifically related to the health of mothers, infants and children. The Millennium Development Goal's (MDG's) are for the hospital to implement the PONEK program (Comprehensive Obstetric Neonatal Emergency Services) for reduce infant mortality and improve maternal health. Maternal and perinatal services must be organized in a teamwork and integrated between medical, nursing, midwifery and support services. The hospital as a health service organization for the community needs to make continuous quality improvement, which continuously improves performance and service quality in order to meet the demands of consumers and the hospital environment.
\end{abstract}

The author has reviewed and approved the final version of the manuscript.

https://doi.org/10.32539/bsm.v5i2.218

\section{Introduction}

The Millennium Development Goals (Millennium Development Goal's) in 2015, there are two targets and indicators that are specifically related to the health of mothers, infants and children. The Millennium Development Goal's (MDG's) are for the hospital to implement the PONEK program (Comprehensive Obstetric Neonatal Emergency Services) for reduce infant mortality and improve maternal health. Maternal mortality generally occurs in groups of women with high risk, namely conditions that threaten the life of the mother / fetus due to a direct result of pregnancy during delivery. High risk pregnancy is estimated to occur $15-20 \%$ of pregnant women, $80 \%$ of maternal deaths occur in the hospital. Maternal mortality in type
A and B hospitals is relatively lower than type C and D hospitals. Neonatal mortality is also closely related to maternal health during pregnancy, childbirth and the management of newborn care, so that neonatal services cannot be separated from services / nursing. her mother. By recognizing the risk factors that lead to mothers including the high risk of regular antenatal surveillance and postnatal surveillance of mothers and their babies, morbility and mortality of mothers and their babies or babies can be reduced or avoided. Maternal and perinatal services must be organized in a teamwork and integrated between medical, nursing, midwifery and support services. 


\section{PONEK Hospital}

The hospital as a health service organization for the community needs to make continuous quality improvement, which continuously improves performance and service quality in order to meet the demands of consumers and the hospital environment. Thus, the more sophisticated the hospital equipment provided and the increasing number of diverse professionals involved in hospital activities, the problems that arise are more numerous and complex.

\section{Main Activities and Activity Details}

The main activities include:

1. Maternal and neonatal health services

Health services for Midwifery, Neonates, IRD (midwifery, children), NICU, ICU, midwifery polyclinic, integrated polyclinic

2. 24 hour PONEK implementation

This implementation involves the emergency room (obstetrics, children), operating room, laboratory, blood transfusion service unit, pharmacy, obstetrics room, neonatal room, NICU and ICU.

3. Inpatient services

Services include IMD, exclusive breastfeeding, kangaroo method care (PMK).

4. Socialization and training of PONEK (Comprehensive Obstetric and Neonatal Emergency Services).

Socialization for the Dr. Mohammad Hoesin Palembang.

5. Training to improve the ability of Human Resources in providing PONEK services.

Felow training for pediatricians, training for midwives and nurses, namely LBW care training, Lactation Management, NICU, ICU.

\section{How to carry out activities}

1. Maternal health services:

a. Midwifery Polyclinic

Every day working hours (Monday to Saturday) serve antenatal care for pregnant women, performed by obstetricians, midwifery residents and midwives, as well as young doctors.

b. Midwifery Room

Maternal care and combined care, carried out by obstetricians, midwifery residents, and midwives, as well as young doctors.

c. ICU Room

Care for pregnant or postpartum women who require intensive care.

2. Neonatal health services

a. Integrated Polyclinic

Every day, working hours (Monday to Saturday) serve healthy and sick neonates, performed by pediatricians, pediatricians, and nurses.

b. Neonatal Room

Nurse for sick babies, performed by pediatricians, pediatricians, and nurses.

c. NICU room

Treatment of sick babies requiring intensive care is carried out by pediatricians, pediatricians and nurses.

3. 24 hour PONEK service

a. Obstetrics IRD

Serving pregnant women who experience maternal emergencies, emergency deliveries to mothers who are about to give birth, carried out by onsite doctors, midwifery residents, and midwives, as well as young doctors.

b. IRD Operating Room

Serving emergencies for mothers who are about to give birth is carried out by specialist obstetricians, midwifery residents and the IRD operating room team.

c. Children's IRD

Providing services to neonates experiencing neonatal emergencies such as resuscitation, performed by onsite pediatricians, child residents, and nurses.

4. Join Care Services 
Performed in the obstetric room for physiological mothers and babies, IMD is performed on mothers who give birth vaginally.

5. Kangaroo Care Method

Performed partially in the neonatal room, NICU in neonates according to the indications for Kangaroo Care Method.

6. Competence Improvement Providing technical guidance for doctors, nurses and midwives.

7. Medical equipment facilities

Complete medical facilities, neonate room, NICU, operating room, midwifery room and IRD.

8. Conducting meetings

9. Hold PONEK TEAM meetings to discuss, among others, the program, strategic planning and monitoring and evaluation periodically every month.

\section{Hour PONEK Hospital criteria}

1. There is a doctor on duty who is trained in the ER to handle both general emergency cases and obstetric-neonatal emergencies. Doctors, midwives and nurses have attended the PONEK team training in hospitals covering neonatal resuscitation, obstetric and neonatal emergencies.

2. Has a Standard Operating Procedure for admission and handling of emergency obstetric and neonatal patients.

3. No down payment policy for patients with obstetric and neonatal emergencies.

4. Has a certain delegation procedure of authority.

5. Have a standard response time in the emergency room for 10 minutes, in the delivery room less than 30 minutes, blood service less than 1 hour.

6. There is an operating room that is ready $(24$ hours standby) to perform operations, if there is an obstetric or general emergency case.
7. There are delivery rooms that are capable of setting up surgery in less than 30 minutes.

8. Having a crew / crew that is ready to carry out operations or carry out tasks at any time, even if they are on call.

9. There is support from all parties in the PONEK service team, including midwives, pediatricians, doctors / anesthetists, internal medicine doctors, other specialists as well as general practitioners, midwives and nurses.

10. Available 24-hour blood service. Guidelines for a 24-hour Comprehensive Emergency Obstetric Neonatal Service Hospital (Ponek)

11. There are other supporting services that play a role in PONEK, such as 24-hour Laboratory and Radiology, 24-hour recovery room, medicines and supporting tools that are always readily available.

12. Equipment, all equipment must be clean (free of dust, dirt, spots, liquids, etc.). Metal surfaces must be free of rust or spots. All equipment must be sturdy (no loose or unstable parts). The painted surface must be intact and free from major scratches. Equipment wheels (if any) must be complete and functional. Instruments ready for use must be sterilized. All electrical equipment must function properly (switches, cables and plugs are firmly attached).

13. Materials. All materials must be of high quality and sufficient in quantity to meet the needs of this unit.

\section{PONEK HOSPITAL SPECIAL CRITERIA}

1. Human Resources

Having an essential PONEK team consisting of: 1 Gynecologist Specialist

1 pediatrician, 1 doctor in the Emergency Unit 3 midwives ( 1 coordinator and 2 supervisors)

2 nurses

Ideal PONEK team plus:

1 Anesthesiologist / nurse anesthetist 
6 Implementing midwives

10 Nurses (every shift 2-3 nurses on duty)

1 Laboratory staff

1 health property

1 Administrative officer

2. Infrastructure and Facilities

In the framework of the Quality Maintaining Program in organizing PONEK, the following must be fulfilled:

Inpatient room is free and comfortable. Emergency action room with complete instruments and materials.

Post-action recovery / observation space Implementation protocols and job descriptions of services including internal coordination

a. Room General Criteria:

1. Physical Structure. Space specifications are not less than 15-20 m

Floors should be porcelain or plastic

The walls should be painted in a material that can be washed or tiled.

2. Cleanliness

Paint and floor should be light colored so that dirt can be seen easily

The room must be clean and free of dust, dirt, trash or hospital waste. This also applies to Floors, furniture, fixtures, instruments, doors, windows, walls, electrical plugs and ceilings.

3. Lighting

Lighting should be bright and natural or electric light. All windows must be screened so that insects do not enter. Electricity must be functioning properly, cables and plugs are not harmful and all lights are functional and sturdy. Emergency equipment available. There should be enough lights for each neonate

4. Ventilation

Ventilation, including windows, should be adequate compared to room size. The fan or air conditioner must work properly. Room temperature should be kept 24-26 $\circ$ C. The air conditioner must be equipped with a filter (preferably antibacterial).

5. Hand washing

The sink should be equipped with an elbow or foot controlled soap or disinfectant dispenser. The sink, faucet and dispenser must be installed at a suitable height (from the floor and walls). There should be no open drains. The hot water supply should be sufficient and equipped with a water heater that is fixed to the wall, suitable plumbing and no exposed wires. There should be a towel (clean cloth) or tissue to dry the hands, placed next to the Westafel.

\section{b. Room Specific Criteria}

1. Handwashing Area in the room in the Obstetrics and Neonate Room In rooms with more than one bed, the bed distance is 6 meters from the sink

2. Resuscitation and stabilization areas in the Obstetrics and Neonates / Emergency Room. The smallest, the room measures 6 meters and is in a Special Care Unit. PONEK rooms in the emergency department must be separated from other emergency rooms. This privacy property is important for the needs of women in labor and babies. The objectives of this room are: to provide emergency services to stabilize the patient's condition, such as shock, cardiac arrest, hypothermia, asphyxia and if necessary help with emergency delivery and resuscitation. It needs to be equipped with an infant resuscitation table and an incubator.

PONEK room requires:

- Space measuring $15 \mathrm{~m}^{2}$ 
- Contains: emergency cabinets and torli

- Maternity beds as well as infusion poles.

- Transport incubator

- Heat transmitter

- Table, chair

- Clean and cool air flow

- Lighting

- Spotlights and emergency lights.

- Suction machine

- Defibrillator

- Oxygen and its cylinder or originating from

- Wall source (outlet)

- Cupboard: maternity kit, vacuum,

- Forceps, curettage, drugs / infusion.

- Adult and infant resuscitation kits

- Sink with running water and antiseptic

- Communication equipment and telephone to the delivery room

- Nurse station and medical record cabinet

- Mobile ultrasound.

Supporting facilities include: toilets, family single rooms, equipment preparation rooms (linen and instruments), dirty boudoirs, guard rooms, sterilizer rooms and paths to the delivery room / operating room are located close to each other and are part of the emergency department.

\section{Maternal Room}

a. The delivery room

The location is close to the Operating Room and the ER

Minimum size: $6 \mathrm{~m}^{2}$ per person. Means that for 1 patient, 1 guardian and 2 helpers needed $4 \times 4 \mathrm{~m}=16 \mathrm{~m}^{2}$. The smallest, a room measuring $12 \mathrm{~m} \quad\left(6 \mathrm{~m}^{2}\right.$ for each patient). There must be a place for isolation of the mother in a separate place. Every mother who gives birth must have privacy so that the family can attend. The delivery room should not be a place for people to pass by. If the operating room is also in the same location, try not to have to cross the delivery room. A minimum of 2 delivery rooms is available in every public hospital. The delivery room is located very close to the neonatal ward, to facilitate the transport of infants with complications to the ward. Ideally a delivery room is an integrated unit: stage 1 , stage 2 and stage 3 which means that each patient is treated as a whole until stage 4 for the mother and her baby - in privacy. If this is not possible, then two rooms for the 1 st stage and one for the 2 nd stage are needed. The delivery room must be close to the nurse's ward to facilitate close supervision after the patient is parturious before being taken to the ward (postpartum). Furthermore, if surgery is needed, the patient will be taken to the operating room adjacent to the delivery room. There should be a bathroom-toilet connected to the delivery room. Postpartum space must be spacious enough, standard: $8 \mathrm{~m}^{2}$ per bed (bed) in a room with multibed or standard 1 bed minimum: $10 \mathrm{~m}^{2}$. The space is separate from the facilities: toilets, bidets, closets. In a room with multiple beds, the minimum distance between the beds is $1 \mathrm{~m}$ to $2 \mathrm{~m}$ and between walls $1 \mathrm{~m}$. Maximum number of beds per room 4. Each room must have windows so that there is sufficient light and air. There should be facilities for washing hands in each room. Each patient should have access to a private bathroom (without the corridor). The examination / diagnostic room contains: patient / ob / gin bed, examiner chair, table, chair, spotlight, tool trolley, small medicine cabinet, mobile ultrasound and emergency trolley. The examination room must have an area of at least $11 \mathrm{~m}$. If there are several 2 beds then per patient requires $7 \mathrm{~m}^{2}$. It is necessary to provide a toilet close to the examination room. Nursing room, nurse stationcontains: table, telephone, cupboard containing emergency / medicine supplies. 
Isolation rooms for cases of infection need to be provided, such as in delivery rooms. Operation room / small emergency / one day care: for curettage, suturing etc. contains: complete operating table, spotlights, small operating equipment cabinet, operator hand wash sink, anesthesia machine, incubator, curette kit (MVA) etc. Waiting room for the patient's family: minimum $15 \mathrm{~m}^{2}$, contains a table, chairs and a telephone.

b. Intensive Care / Eclampsia / Sepsis Unit. This unit should be located next to the delivery room, or at least away from areas with frequent traffic. The smallest, a room measuring $18 \mathrm{~m} 2$ (6-8 $\mathrm{m}$ for each patient) In a room with multiple beds, there should be at least 8 feet $(2.4 \mathrm{~m})$ of space between the mother's beds. The room shall be equipped with at least six power plugs properly fitted to the electrical appliance. The plug must be able to supply the necessary electrical load, be safe and function properly

\section{Neonatal Room}

a. Intensive care unit This unit should be located next to the delivery room, or at least away from areas that are frequently traveled, Minimum room size is $18 \mathrm{~m} 2$ (6$8 \mathrm{~m}$ for each patient) In rooms with multiple beds at least 8 feet apart $(2.4 \mathrm{~m})$ between cots. There should be space for the isolation of infants in separate areas. The room should be equipped with at least six properly fitted plugs for electrical appliances,

b. Special Care Unit

This unit should be at the side of the delivery room, or at least away from an area with frequent traffic. Minimum room size of $12 \mathrm{~m}^{2}$ (4 $\mathrm{m}$ for each patient) There must be a place for isolation of infants in separate areas. There should be at least 1 $m$ distance between the incubator or baby cot

c. Lactation area

Minimum room size is $6 \mathrm{~m}^{2}$

d. Incubator wash area

Minimum room size is $6-8 \mathrm{~m}^{2}$

\section{Operation Room}

Operating units are required for cesarean section and laparotomia. Ideally an operating room has an area: $25 \mathrm{~m}^{2}$ with a minimum width of $4 \mathrm{~m}$, excluding facilities: wall cabinets. This unit has at least one section on obstetrics. A communication unit with the delivery room should be provided. In the operating room should be available: a heat transmitter, incubator and resuscitation equipment for adults and infants. This resuscitation room measures: $3 \mathrm{~m}$. There must be 6 sources of electricity. The recovery room is a room for post-surgical patients with a standard area: $8 \mathrm{~m} /$ bed, there are at least 2 beds, besides that the contents of the room are: a table, a nurse's chair, a medicine cabinet, an oxygen pulse monitoring machine, etc., a medical record place, baby incubator, emergency trolley. Direct supervision from the nurse's desk to the patient's premises should be possible. Likewise, so that families can see through the glass. It is necessary to provide communication tools to the delivery room and operating room, as well as a telephone. At least there are 4 sources of electricity / bed. The following service facilities need to be provided for the operating unit:

- Nurse station which also functions as a place for people traffic control.

- Workspace - dirty which is separate from the clean workspace - this room functions to clean up dirty tools and cloths. Large washbasins for hand washing and hot / cold water facilities should be provided. There is a work table and chairs, a trolley trolley.

- Sewage / liquid drains.

- KO supervisor room: $10 \mathrm{~m}^{2}$

- Family waiting area: available chairs, tables 
and available toilets

- Sterilization room linked to the operating room. There is a large autoclave handy in case of emergency.

- Medicine room contains cupboards and tables for drug distribution.

- Hand washing room (scrub) for at least two people, located in front of the room

- Operation / delivery room. The sink must be designed so that it does not wet the floor. Hand washing water must be sterile.

- Clean workspace. This room contains a table and a cupboard filled with linen, clothes and surgical supplies. There is also a linen carrying trolley.

- Gas room / gas cylinder

- Anesthetic equipment warehouse: tools / machines that are being repaired-cleaned, tables and chairs

- $12 \mathrm{~m}$ warehouse: a place for the tools of the delivery room

- and operating room

- changing rooms: men and women $12 \mathrm{~m}$ each, containing lockers, tables, chairs and sofas / beds, there is a $3 \mathrm{~m}$ toilet.

- Discussion rooms for staff and paramedics: $15 \mathrm{~m}^{2}$.

- Doctor's ward: $15 \mathrm{~m}^{2}$

- Paramedic ward: $15 \mathrm{~m}^{2}$

- House keeping: contains cabinets, tables, chairs, suction machines, brooms, buckets, cleaning supplies, etc.

- Space to accommodate gurneys and pushchairs.

6. Supporting rooms must be provided such as:

- Nurse / midwife room

- Nurse's office

- Medical record room

- Staff toilet

- Medical staff room

- Staff / nurse locker rooms

- Meeting / conference room

- The patient's living room
- Laundry room

- Preparation space is required when there are equipment warehouse tools / materials preparation activities

- Dirty rooms - utensils - must be separate from washing / sterile rooms. This room has a washing place with hot-cold water, there is a table for work.

- Medicine room: sink, work table etc.

- Room clean linen.

- Small kitchen for patient sharing.

3. Supporting Infrastructure and Facilities

a. Blood Transfusion Unit

This unit must function to carry out compatibility tests, donor collection and lab tests: VDRL infection, hepatitis, HIV. It takes $25 \mathrm{~m}^{2}$ of space, contains refrigerators, tables and chairs, cabinets, telephones, staff rooms, etc. Having equipment in accordance with the minimum standards of maternal and neonatal equipment. Hospitals that do not have blood transfusion unit / blood bank facilities are recommended to make cooperation with the providers of these facilities.

b. Laboratory

This unit must function to perform laboratory tests in the handling of maternal emergencies in supporting hemostasis examinations for preeclampsia and neonatal care.

c. Radiology and ultrasound

This unit should serve for the diagnosis of Obstetrics and Thorax

\section{References}

1. Laporan Tahunan 2013. Rumah Sakit Umum Pusat Dr. Mohammad Hoesin Palembang

2. Aditama TY. 2010. Manajemen Administrasi Rumah Sakit. Edisi kedua. Penerbit Universitas Indonesia. Jakarta 
3. Adikoesoemo, S. 2002. Manajemen Rumah Sakit, Pustaka Sinar Harapan, Jakarta.

4. Azwar, A. 1996, Pengantar Administrasi Kesehatan, FKUI, Binarupa Aksara. Jakarta.

5. Azwar, A.1994. Program Menjaga Mutu Pelayanan Kesehatan : Aplikasi Prinsip Lingkaran Pemecahan Masalah. Yayasan Penerbitan Ikatan Dokter Indonesia. Jakarta.

6. Djojodibroto, D, 1997. Kiat Mengelola Rumah Sakit, Hipokrates, Jakarta,

7. Gaspersz, V, 2005. Total Quality Management. PT Gramedia, Cetakan keempat, Jakarta.
8. Kotler P., 1997, Manajemen Pemasaran, edisi 11. PT.Indeks Kelompok Gramedia, Jakarta.

9. Anderson, J.C., Rungtusanatham, M., Schroeder, R.G. (1994), "A Theory of Quality Management Underlying the Deming Management Method" Academy of Management Review,Vol. 19, No. 3

10. Carmona, Salvador dan Anders Gronlund (2003), "Measures vs Action: the Balanced Scorecard in Swedish Law Enforcement",International Journal of Operation and Production Management, Vol. 23, No. 12 